REVISTA

MEXICANA DE

ECONOMÍA Y

FINANZAS

REMEF

(TIIE MEXICAN JOURNAL OF

ECONOMICS AND FINANCE)
Revista Mexicana de Economía y Finanzas, Nueva Época

Volumen 16 Número 4, Octubre - Diciembre 2021, pp. 1-23, e621

DOI: https://doi.org/10.21919/remef.v16i4.621

(First reception: May 11, 2020, Last reception: November 25, 2020, Accepted: November 30, 2020, Published: March 30, 2021)

\title{
Simulation of Levelized Costs of Electricity Considering Externalities
}

\author{
Maria del Carmen Gomez-Rios ${ }^{1}$ - Universidad Anáhuac, México \\ Dora Galvez-Cruz ${ }^{2}$ - Universidad Anáhuac, México
}

This research presents long-term projects. Applies stochastic models using Monte Carlo simulation to identify the impact that changes have in the input parameters on the output variable (LCOEE). Uses tornado analysis to identify the impact of the input variables. The results show that; in thermoelectric coal plant, the LCOEE is more sensitive to changes in the price of $\mathrm{CO} 2$ emissions than discount rate. In the combined cycle, the LCOEE is most sensitive to the plant factor than $\mathrm{CO} 2$ emissions price, discount rate. In the nuclear power plant, the discount rate has greater impact on the LCOE than overnight cost. In contrast to previous work, this research uses Mexico's country-risk in the discount rate. This research's limitation is that the costs related to transmission, distribution, and backup fee are not included. Concluding that stochastic models provide useful information for decision-making by incorporating historical data and projections of the main variables that could affect the output variable (LCOEE).

JEL Classification: C50, C53, C60, D81, Q40, Q53.

Keywords: Monte Carlo simulation, Levelized cost, Electricity, Baseload power plants, Environmental externalities.

\section{Simulación de costos nivelados de electricidad considerando externalidades}

Esta investigación presenta proyectos de largo plazo. Aplica modelos estocásticos mediante simulación de Monte Carlo para identificar el impacto que los cambios en los parámetros de entrada tienen en la variable de salida (LCOEE). Utiliza análisis de tornados para identificar el impacto de las variables de entrada. Los resultados muestran; en termoeléctrica de carbón, que el LCOEE es más sensible a los cambios en el precio de las emisiones de CO2 que a la tasa de descuento. En el ciclo combinado, el LCOEE es más sensible al factor de planta que al precio de las emisiones de CO2. En la central nuclear, la tasa de descuento tiene mayor impacto en el LCOE que el costo unitario de inversión. A diferencia de trabajos anteriores, se usa el riesgo país de México en la tasa de descuento. Limitaciones: los costos relacionados con la transmisión, distribución y tarifa de respaldo no están incluidos. Concluyendo que los modelos estocásticos brindan información útil para la toma de decisiones al incorporar datos históricos y proyecciones de las principales variables que podrían afectar al LCOEE.

Clasificación JEL: C50, C53, C60, D81, Q40, Q53.

Palabras clave: Simulación Monte Carlo, costo nivelado, energía eléctrica, centrales generadoras de carga base, externalidades ambientales.

\footnotetext{
${ }^{1}$ Corresponding author. Quinto piso del CAIDE. Universidad Anáhuac México, campus Norte. Av. Universidad Anáhuac 46, Col. Lomas Anáhuac, Huixquilucan, Estado de México, México. C. P 52786. Teléfono: 56270210. Ext. 8210. E-mail: carmen.gomez@anahuac.mx

* No source of funding for research development
} 


\section{Introduction}

This research aims to compare the cost per MWh. generated in baseload plants of electricity; coal thermoelectric, combined cycle, and nuclear power plants, which operate 24 hours a day, 365 days a year. Likewise, environmental externalities are incorporated into coal and combined cycle plants' costs, to compare these technologies in equal circumstances with nuclear power plants that do not emit $\mathrm{CO}_{2}$ in their electricity generation process.

Since the first decades of the year 2000, there has been an electricity market liberalization at international level (Jamasb \& Pollitt, 2005), and in particular in Mexico, from 2010 to 2018, in which the entry of private investors in the generation of electricity was allowed (Brown del Rivero \& Brown del Rivero, 2011). This activity was previously reserved for the government and which had budgetary resources, somehow unlimited, to cover the electricity demand. With limited resources and justifying the projects, private investors have found themselves in need of models that allow them to incorporate the uncertainty of the different economic and financial variables that affect the costs that power generating plants face.

For determining the diversification effects on energy portfolios, different methodologies have been used, and in some cases, these methodologies include externalities. The LCOE (Levelized Cost Of Energy) has been widely used to calculate the lifetime unit cost of electricity generated (Shen, et al., 2020) (Matheu, 2014) (Vithayasrichareon P. M., 2010). Besides, Aldersey-Williams et al. (Aldersey-Williams \& Rubert, 2019) have identified three additional expenditures of energy metrics; Undiscounted cost of energy (UCOE), discounted costs cost of energy (DCCOE), and total cost of energy (TCOE). The "undiscounted cost of energy divides the total capital and operational costs by the energy produced" (Aldersey-Williams \& Rubert, 2019). The UCOE is useful to compare projects with the same technologies; however, it cannot compare between different technologies types. The "discounted costs cost of energy divides the discounted sum of operational and capital costs by the sum of energy produced" (Aldersey-Williams \& Rubert, 2019); however, this metric is not redeemed as useful since "it returns a figure that does not clearly relate to a price required for a project" (Aldersey-Williams \& Rubert, 2019). Finally, the total cost of energy includes the financial cost and divides the total project cost by the energy produced.

In some cases, the LCOE has been modified to include externalities, such as Lucheroni's et al. (Lucheroni \& Mari, 2017), that used stochastic LCOE to include uncertainties such as financial risks in nuclear technology. They used two measures of risk; a standard deviation and CVaR deviation. They found that the volatility in the price of $\mathrm{CO}_{2}$ emissions has a strong influence on the portfolio's risk.

In general, electricity generation projects do not consider environmental costs $\left(\mathrm{CO}_{2}\right.$ emissions) within their cost structure, so the projects that use fossil fuels have additional benefits by underestimating their total costs. Lacatelli et al. (Locatelli \& Mancini, 2010) used LCOE to analyze the financial performance and influence of $\mathrm{CO}_{2}$ cost in small and medium-sized nuclear, coal, and gas power plant using LCOE. They found that if $\mathrm{CO}_{2}$ has no taxes included in the technologies with fossil combustibles, their levelized costs are smaller than the nuclear plant; however, the costs are higher when taxes are included. Hence the interest of the leading world organisms is that the plants that use 
fossil fuels to generate electricity incorporate the environmental costs (Agency, International emission trading - From Concept to Reality, 2001) (NEA, 2003) (Agency, Act Locally, Trade Globally: Emissions Trading for Climate Policy, 2005), to be able to compare their levelized cost of electricity with those of technologies that do not emit $\mathrm{CO}_{2}$ into the environment, such as nuclear.

On the other hand, the Monte Carlo analysis has been used to solve uncertainties in LCOEs. Such as the case of Riesz et al. (Riesz, Sotiriadis, Vithayasrichareon, \& Gilmore, 2017) that used 10,000 Monte Carlo simulations that included overnight capital cost (OCC), the degree of cost escalation over the construction and pre-construction periods, and the duration of those periods. Since externalities are included in this research, the use of Monte Carlo analysis provides a better understanding of its impact on the LCOE. It is essential to notice that externalities are understood as "the economic and social activities of a group of people that negatively impact another group, and the latter only receives partial compensation, or receives no compensation from the first group for the damage caused." (NEA, 2003). It also should be noted that nuclear power plants do not emit $\mathrm{CO}_{2}$ in their electricity generation process.

The contributions of this research are; the use of stochastic models in the levelized cost of electricity with externalities (LCOEE) of baseload plants, coal thermoelectric, combined cycle, and nuclear. To compare which technology has both the lowest risk and LCOEE.

Since the tornado model identifies the impact of each of the input variables on the LCOE, this research also uses tornado analysis in each technology to determine which variables have a bigger influence on the LCOEE.

This research also contributes to the use of the commercial interest reference rates (CIRR), which is the discount rate used in long-term projects in the OECD member countries. Mexico's country risk factor is also incorporated into the CIRR to determine a discount rate applied to longterm projects in the electricity generation sector in Mexico. It uses projections of coal, natural gas, and nuclear fuel prices for the period 2017-2040.

This research's limitation is that the costs related to transmission, distribution, and backup fee are not included. The reason is that this research's objective was to calculate the LCOEE and not the sale price of the electricity. Another limitation is related to the emissions' price, in this case, it is important to note that a daily series of $\mathrm{CO}_{2}$ emission prices are used from January 15, 2012, to December 15, 2017, and the average, maximum, and minimum value are selected. With which the simulation is fed.

The first section introduces the methodology of the levelized cost of electricity with externalities (LCOEE). The second section presents the stochastic method to obtain a function that indicates where the LCOEE could be found with a high level of probability since the input variables follow probability distributions that can be simulated by the Monte Carlo procedure. In the third section, the stochastic models of the technologies analyzed are compared with those obtained in the deterministic model, and the tornado analysis is applied. Finally, discussion, conclusions, and proposals for future work are presented. 


\section{Literature review}

Electricity is one of the vital resources that countries have; hence, it is essential to obtain an accurate calculation of its generation's cost. Amongst the methodologies to calculate the cost of generation of electricity, four methodologies can be identified; the undiscounted cost of energy (UCOE), the discounted costs cost of energy (DCCOE), the total cost of energy (TCOE), and the levelized cost of electricity (LCOE) (Aldersey-Williams \& Rubert, 2019). The UCOE is a division of the total capital and operational costs by the energy produced. The UCOE is a useful method to compare the full price of projects; however, the externalities' impact in the final calculation is not clearly stated and has a clear disadvantage when used while comparing different technologies. The DCCOE is a division of the sums of discounted operational and capital costs by the energy produced. This method's disadvantage is mainly in long-term projects since the discount factor has a more significant impact on the flows of the last years of the project. The TCOE includes the financing cost in the total project cost and divides it by the energy produced. In this case, the costs are considered "over the full project life, allowing for inter-year variability in costs" (Aldersey-Williams \& Rubert, 2019).

Finally, the LCOE, firstly published by the NEA (nuclear energy agency) in 1981 (Nuclear Energy Agency (NEA) e International Energy Agency (IEA), 2015) in cooperation with twelve different countries, "indicates the unit costs of electricity over the full life or economic life of a project and is widely used to measure the feasibility and competitiveness compared to other technologies" (Nuclear Energy Agency (NEA) e International Energy Agency (IEA), 2015). From its publication onwards, the methodology has been used as a reference to calculate the levelized costs of baseload, nuclear, and coal. Important changes have been present during the eight editions of this methodology, such as setting the currency to USD, the use of three different discount rate; $3 \%, 7 \%$, and $10 \%$ to the analysis of the levelized costs. The equation to calculate the LCOE uses the lifecycle cost and the lifetime electricity production, hence obtaining the average long-term cost needed to generate a production unit in megawatts per hour (MWh). The importance of the LCOE is considerable since the European Bank for reconstruction and development (European Bank For Reconstruction And Development, 2014) has stated that every financing for the assessment of coal and associated infrastructure in the period 2014 - 2018 needed to fulfill the LCOE methodology.

For instance, Denmark has developed economic models to optimize decision-making in the electricity system and ensure the competitiveness of its economy. A low initial investment does not necessarily mean a cheap energy supply for society; it is of great importance to consider the quality of supply, security, and externalities. The Danish Energy Agency (DEA) has developed an electric power cost calculator, based on the LCOE methodology, to assess the average costs of supplying one MWh for different technologies. This tool helps to compare and select optimal technologies in the future; it also allows specific comparisons of average costs of conventional and new technologies between partner countries (Danish Energy Agency, 2020).

On the other hand, Roques et al. (Roques F. A., 2006-07) review the traditional level cost limits for evaluating electricity generation investments in liberalized markets since it does not incorporate the impact of uncertainty on key parameters of production costs or future revenues. The authors report that including nuclear energy in a portfolio with a high share of gas mitigates the 
probability of suffering large losses due to the uncertainty in the price of gas and $\mathrm{CO}_{2}$ emissions, without major negative impacts on the expected NPV. Therefore, investors are faced with a trade-off, maximize expected returns, or minimize the risk exposure of their investment. They conclude that the Monte Carlo simulation, when used correctly, is an advantageous tool for making investment decisions for the resources of electricity-generating companies.

The LCOE is useful to the strategic planning of a country's electric system, such as Australia's case. Riesz et al. (Riesz, Sotiriadis, Vithayasrichareon, \& Gilmore, 2017) used the LCOE to evaluate the economic viability of implementing a nuclear power plant construction program in Australia for the following two decades from the research and reducing $\mathrm{CO}_{2}$ emissions. Australia generates $80 \%$ of its electricity with coal-fired thermoelectric plants and has no nuclear power plants. A Monte Carlo model was applied to obtain the LCOE; they used 10,000 simulations to incorporate a source of uncertainty in nuclear power plants, investment cost (overnight cost), construction time, escalation of capital costs in construction, and construction delays. This research concluded that, given Australia's endowment of coal and renewable resources (sun and wind), it would not be advisable to implement a nuclear energy program because it has significantly high LCOEs compared to coal, solar, and wind.

Different variations of the LCOE methodology have been used to find the costs of generating energy according to the generation source. The review presented by Shen et al. (Shen, et al., 2020) includes costs to the LCOE to obtain a more detailed calculation of variable renewable energy (VRE) to solve climate change. The costs include investment, operational, plant performance, uncertainty, and risk. They found that they could use the LCOE to obtain and calculate the levelized revenue of VRE.

Other authors have used the LCOE for comparing the average levelized cost of energy from existing generation plants to the LCOE from new generation resources. The analysis includes environmental regulations the reduction of electricity prices, ans subsidies on renewable energies. They identify what other costs need to be included, such as cost of taxes and determine that the LCOEs of existing coal, hydro, gas and nuclear technologies are less than building and operating new plants to replace them. For an existing coal plant, the average LCOE is $\$ 41 / \mathrm{MWh}$, while the projected LCOE for a new coal plant operating a similar duty cycle would be $\$ 71$ / MWh. Similarly, they estimate that existing gas plants can generate electricity at an average LCOE of \$36 / MWh and a projected LCOE of \$ 50 / MWh (Thomas F. Stacy, The Levelized Cost of Electricity from Existing Generation Resources, 2019). When the electrical system accepts renewable energy, it displaces the electricity from base charging centers and increases their LCOE.

Wind and solar resources increase the LCOE of baseload technologies as they have to reduce their plant factors, which causes an increase in their levelized costs. Stacy et al. (Thomas F. Stacy, The Levelized Cost of Electricity from Existing Generation Resources, 2019) indicate that the "imposed cost" that wind energy adds to the combined cycle is estimated at \$24 / MWh, due to the electricity it could displace. In the case of solar energy, it would be \$21 / MWh. In such a way that the LCOE of new wind or solar plants should include in their level costs said "imposed cost" that they cause to other electricity generation technologies.

On the other hand, stochastic methods provide more information to assist with medium and long-term investment decision-making projects. It considers the historical data and the forecasts of the variables that feed the simulation models. Incorporating the uncertainty and providing a range 
of values where the variables of interest could be found with a high probability. Hence, it reduces the risk in investments (Mari, 2020) (Lucheroni \& Mari, 2017). They also found that incorporating nuclear energy into the coal and gas energy portfolio reduces the risk and $\mathrm{CO}_{2}$ emissions on the portfolio.

Additionally, the use of deterministic models is no longer sufficient to assess the economic viability of long-term projects (Roques F. , 2006) (Karkhov, 2002); therefore, the need to incorporate stochastic models (Hrafnkelsson, 2016), where Monte Carlo simulation is used. Monte Carlo is a simulation technique that, under different probability distributions, allows to estimate expected values for uncontrollable variables (Khindanova, 2013) (Faulín, 2005).

In the case of the electric industry, the Monte Carlo simulation has been successfully applied in the evaluation of projects (Rode, 2001), (Khindanova, 2013), (Vithayasrichareon P. a., 2010) and (Wada, 2014).

This research uses the methodology of Levelized Cost of Electricity (LCOE), developed by NEA / IEA (Nuclear Energy Agency (NEA) e International Energy Agency (IEA), 2015) and International Energy Agency (IAEA Nuclear Energy Series, 2016), to estimate the cost per MWh generated. The deterministic model is applied to the technologies; coal thermoelectric, combined cycle, and nuclear power plants, where the input and output parameters are fixed. This research also incorporates environmental externalities through the $\mathrm{CO}_{2}$ emissions generated in thermoelectric coal plants and combined cycle power plants.

As stated previously, this research uses the tornado analysis to identify how sensitive is the LCOEE to changes in the input parameters. That is, tornado analysis helps determine the degree to which input parameters contribute to the uncertainty of the LCOEE. The tornado diagram summarizes the impact of each input parameter. Typically, this analysis assumes that these parameters are statistically independent. The greatest impact parameters are placed at the top in the tornado graph, while the least impact parameters stay at the bottom. Thus, the graph is shaped like a tornado. In this way, the investor can easily identify the input parameters to which he should pay more attention. Tornado analysis requires defining a test range. For the present research, the $5 \%$ to 95\% percentile range is taken (Eschenbach, 2006).

The present work differs from the existing ones in three aspects:

1. Several sources of uncertainty are considered at once in the Monte Carlo simulation: a) the power plants' efficiency, b) the price of $\mathrm{CO}_{2}$ emissions, c) the overnight cost, and d) the interest rate; to obtain the LCOEE of the three leading baseload technologies.

2. The Tornado analysis is obtained for the three technologies, and the variables to which the LCOEE is most sensitive are identified.

3. The LCOEE obtained from the deterministic and stochastic model are compared.

\section{Methodology of the Levelized Cost of Electricity (LCOE)}

This section briefly describes the methodology indicated by the NEA / IEA (Nuclear Energy Agency (NEA) e International Energy Agency (IEA), 2015) to estimate the Levelized Cost of Electricity with Environmental Externalities (LCOEE), which will be applied to the three traditional baseload 
technologies: a) coal thermoelectric with $772 \mathrm{MW}$ capacity, b) combined cycle using natural gas with 551 MW capacity and c) nuclear power plant equipped with an ABWR reactor (Advanced Boiling Water Reactor) of 1,425 MW of installed capacity.

To determine the LCOEE, the sum of the Levelized investment cost (CNI, in Spanish), the Levelized cost of fuel with environmental externalities (CNCE, in Spanish), and the levelized of operation and maintenance cost (CNOM, in Spanish) are performed.

According to Gómez-Ríos (Gómez-Ríos M.-d.-C. , 2008) (Gómez-Ríos M. d., 2016), the Levelized Cost of Electricity with Environmental Externalities (LCOEE) can express as:

$$
L C O E E=C N I+C N C E+C N O M
$$

where

CNI:= Levelized Investment Cost

$C N C E:=$ Levelized Cost of Fuel with $\mathrm{CO}_{2}$ Externalities

CNOM:= Levelized Operation and Maintenance Cost

The LCOEE indicates the monetary amount that must be allocated for the construction of the plant (levelized investment cost), to cover fuel costs and compensate society for externalities caused by $\mathrm{CO}_{2}$ emissions in the electricity generation process, as well as the operation and maintenance costs for each MWh generated.

\subsection{Estimation of the Levelized Cost of Electricity with Environmental Externalities (LCOEE) using the Deterministic Method}

\subsubsection{Levelized Investment Cost}

In this section, the deterministic method is applied to estimate the Levelized Investment Cost (CNI, in Spanish) for the three technologies that are considered in this document which are: A) coal thermoelectric, B) combined cycle and C) nuclear power plant equipped with an ABWR reactor. In this method, the input parameters cannot be modified throughout the operational life of the exchanges and a single output result is obtained.

Next, the main characteristics of the three base load technologies that are analyzed are mentioned.

\section{A. Coal Thermoelectric}

The main characteristics that can be mentioned of coal thermoelectric plants (CT) are: a) it is a capital-intensive technology so that any movement in interest rates significantly affects investment costs; b) the share of fuel costs in its operation represents approximately $50 \%$ of the total costs, so any upward movement of coal strongly impacts the cost of fuel; c) it is a technology with a long economic life (40 years of operation), and d) emits $\mathrm{CO}_{2}$ to the environment in its electricity generation process. 


\section{B. Combined Cycle}

In the case of the combined cycle plants (CC): a) it is a technology that requires a low level of investment, hence variations in interest rates do not have a strong impact on investment costs; $b$ ) the share of the cost of fuel is high, around $75 \%$, thus, the variations in natural gas prices significantly impact fuel costs; c) has an economic life of 30 years and d) emits carbon dioxide $\left(\mathrm{CO}_{2}\right)$ to the environment.

\section{Nuclear Power Plant}

Nuclear power plants have the following characteristics: a) capital-intensive technology, so that any movement in interest rates significantly affects investment costs; b) the share of fuel costs in its operation are relatively low (15\%) so that upward movements of nuclear fuel (uranium) slightly affect fuel costs; c) it is a technology with a long economic life (60 years of operation); and d) does not emit $\mathrm{CO}_{2}$ into the environment.

Table 1 shows the input parameters to calculate the levelized investment cost (CNI, in Spanish) of the three technologies, published by the NEA / IEA (Nuclear Energy Agency (NEA) and International Energy Agency (IEA), 2015).

Table 1. Input parameters to calculate the CNI.

\begin{tabular}{|c|c|c|c|c|}
\hline Concept & Units & CT & CC & Nuclear \\
\hline Capacity & MWe & 772 & 551 & 1,425 \\
Capacity factor & $\%$ & $85 \%$ & $85 \%$ & $85 \%$ \\
Own uses & $\%$ & $10.6 \%$ & $3.0 \%$ & $3.5 \%$ \\
Overnight cost & USD $/ \mathrm{kWe}$ & 2,271 & 1,108 & 5,241 \\
Economic life & years & 40 & 30 & 60 \\
Annual discount rate & $\%$ & $4.84 \%{ }^{3}$ & $4.84 \%$ & $4.84 \%$ \\
\hline
\end{tabular}

Based on data obtained from Nuclear Energy Agengy (Nuclear Energy Agency (NEA) and International Energy Agency (IEA), 2015)

The construction of this type of base load plants is carried out in more than one year, so several annual expenditures have to be carried out during their construction process.

Applying the methodology of Levelized Investment Cost (CNI), the amount of investment is obtained without and with interest, gross and net generation, as well as the same CNI of each of the plants, which are presented in Table 2.

\footnotetext{
${ }^{3}$ Stochastic
} 
Table 2. Levelized Investment Cost (CNI) - Deterministic Model Coal Thermoelectric, Combined Cycle and Nuclear Plant

\begin{tabular}{|l|c|c|c|c|}
\hline \multicolumn{4}{|c|}{ CNI - DETERMINISTIC MODEL } & \\
\hline Concept & Units & CT & CC & Nuclear \\
\hline Investment not include capital & & & 610.5 & \\
cost & Millions of USD & $1,753.5$ & & $7,468.4$ \\
Investment include capital cost & Millions of USD & $2,001.1$ & 668.4 & $8,520.1$ \\
Annual gross electricity & & & $4,102,746$ & \\
generation & MWh & $5,748,312$ & & $10,610,550$ \\
Annual Net electricity generation & MWh & $5,138,991$ & $3,979,664$ & $10,239,181$ \\
CNI & USD/MWh & $\mathbf{2 1 . 1 9}$ & $\mathbf{1 0 . 2 4}$ & $\mathbf{4 0 . 8 4}$ \\
\hline
\end{tabular}

Based on data obtained from Nuclear Energy Agency International Energy Agency (Nuclear Energy Agency

(NEA) e International Energy Agency (IEA), 2015)

\subsubsection{Levelized Cost of Fuel with Externalities}

To determine the cost of fuel in the coal plant with a capacity of $772 \mathrm{MW}$, the projections of the price of coal published by NEA / IEA for the period 2017-2040 (Annual Energy Outlook, 2017) are used. The levelized cost of fuel is $\$ 40.61 \mathrm{USD} / \mathrm{MWh}$.

In the case of the combined cycle with a capacity of $551 \mathrm{MW}$, the projections of natural gas prices were considered (Johns Hopkins School of Advanced International Studies, 2017). The estimation of the levelized cost of fuel is \$48.44 USD / MWh.

In order to include the externalities of $\mathrm{CO}_{2}$ in the thermoelectric coal plant and in the combined cycle, the $\mathrm{CO}_{2}$ emissions reported by COPAR (Federal Electricity Commission (CFE), 2014) are considered, being 730.0 kilograms of $\mathrm{CO}_{2}$ per $\mathrm{MWh}$ generated in the coal plant and 376.9 kilograms of $\mathrm{CO}_{2}$ per $\mathrm{MWh}$ in the combined cycle. The average price used to value emissions is $\$$ 7.4892 per ton of $\mathrm{CO}_{2}$ emitted to the environment, Section 2.1 presents the estimations made to obtain this value. The price was estimated from a daily historical series from January 2012 to December 2017 published on the website Market insider (Markets Business Insider, 2017). The $\mathrm{CO}_{2}$ emissions of fossil technologies are multiplied by the annual gross electricity generation and subsequently by the price of the ton of $\mathrm{CO}_{2}$. In the coal plant, a levelized cost of $\mathrm{CO}_{2}$ emissions of $\$ 6.12$ USD / MWh is obtained. In the 40 years of operation, 167.9 million tons of $\mathrm{CO}_{2}$ would be generated. In the combined cycle, a levelized cost of $\$ 2.91$ / MWh would be obtained, and in the 30 years of operation 46.4 million tons of $\mathrm{CO}_{2}$ would be emitted.

The levelized cost of fuel considering externalities (CNCE) for the coal plant is \$46.73 USD / MWh and \$51.35 USD / MWh for the combined cycle. In the case of the nuclear power plant, since it does not emit $\mathrm{CO}_{2}$ into the environment, the cost of fuel is only \$9.33 USD / MWh. ( (Nuclear Energy Agency (NEA) e International Energy Agency (IEA), 2015). See Table 3. 
Table 3. Levelized Cost of Fuel with Externalities (CNCE) Coal Thermoelectric, Combined Cycle and Nuclear Plant

\begin{tabular}{|l|c|c|c|}
\hline \multicolumn{3}{|c|}{ CNCE - DETERMINISTIC MODEL } & \\
\hline & CT & CC & Nuclear \\
\hline Fuel Levelized Cost & $\$ 40.61$ & $\$ 48.44$ & $\$ 9.33$ \\
\hline $\mathrm{CO}_{2}$ Levelized Cost & $\$ 6.12$ & $\$ 2.91$ & $\$ 0.0$ \\
\hline CNCE & $\mathbf{\$ 4 6 . 7 3}$ & $\mathbf{\$ 5 1 . 3 5}$ & $\mathbf{\$ 9 . 3 3}$ \\
\hline
\end{tabular}

Based on data obtained from (Nuclear Energy Agency (NEA) e International Energy Agency (IEA), 2015)

\subsubsection{Levelized Operation and Maintenance Cost}

The levelized operation and maintenance (CNOM) cost for the coal plant is $\$ 12.44$ USD / MWh. In the combined cycle, \$4.79 USD / MWh. And at the nuclear power plant \$11.0 USD / MWh. (NEA / IEA (Nuclear Energy Agency (NEA) e International Energy Agency (IEA), 2015).

\subsubsection{Levelized Cost of Electricity with Environmental Externalities (LCOEE)}

The result of the LCOE with externalities using the deterministic model is obtained by adding the previously calculated levelized costs for each of the technologies, as shown in Table 4.

Table 4. Levelized Cost of Electricity with Environmental Externalities (LCOEE) Coal Thermoelectric, Combined Cycle and Nuclear Plant - USD/MWh

\begin{tabular}{|l|c|c|c|c|c|c|}
\hline & \multicolumn{2}{|c|}{ CT } & \multicolumn{2}{c|}{ CC } & \multicolumn{2}{c|}{ Nuclear } \\
\hline Levelized Investment Cost & $\$ 21.19$ & $26.4 \%$ & $\$ 10.24$ & $15.4 \%$ & $\$ 40.84$ & $66.8 \%$ \\
\hline $\begin{array}{l}\text { Levelized Cost of Fuel with } \\
\mathrm{CO}_{2} \text { Externalities }\end{array}$ & $\$ 46.73$ & $58.2 \%$ & $\$ 51.35$ & $77.4 \%$ & $\$ 9.33$ & $15.3 \%$ \\
\hline $\begin{array}{l}\text { Levelized Operation and } \\
\text { Maintenance Cost }\end{array}$ & $\$ 12.44$ & $15.5 \%$ & $\$ 4.79$ & $7.2 \%$ & $\$ 11.00$ & $18.0 \%$ \\
\hline LCOEE & $\mathbf{\$ 8 0 . 3 6}$ & $\mathbf{1 0 0 . 0 \%}$ & $\mathbf{\$ 6 6 . 3 8}$ & $\mathbf{1 0 0 . 0 \%}$ & $\mathbf{\$ 6 1 . 1 7}$ & $\mathbf{1 0 0 . 0 \%}$ \\
\hline
\end{tabular}

Based on data obtained from (Nuclear Energy Agency (NEA) e International Energy Agency (IEA), 2015) and (Federal Electricity Commission (CFE), 2014)

Table 4 shows that the levelized cost of fuel with $\mathrm{CO}_{2}$ externalities in $\mathrm{CT}$ and CC plants, have the highest percentage within the LCOEE, exceeding 50\% in the case of coal and reaching $77.4 \%$ in the combined cycle. While the nuclear power plant has the lowest cost of fuel.

Image 1, shows the share of the levelized costs within the LCOEE of each of the technologies analyzed. It can be seen that, in the case of the nuclear power plant, the levelized investment cost represents the largest share $(66.8 \%)$, while in the combined cycle, the fuel with $\mathrm{CO}_{2}$ externalities is by far the most representative $(77.4 \%)$. 


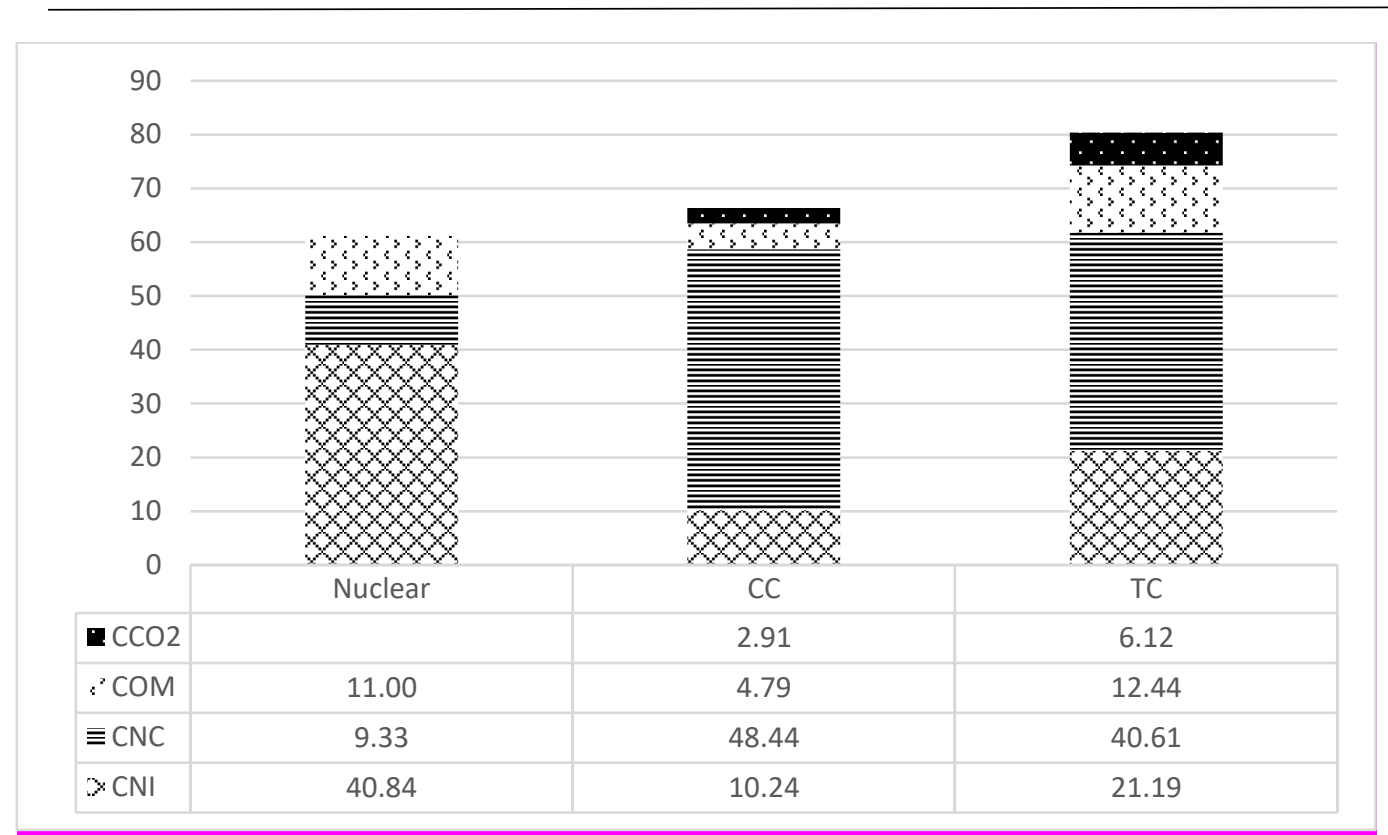

Image 1. Share of levelized costs within the LCOEE Coal Thermoelectric, Combined Cycle and Nuclear Plant.

Source: Based on data obtained from (Nuclear Energy Agency (NEA) e International Energy Agency (IEA), 2015) and (Federal Electricity Commission (CFE), 2014)

Once the results of the deterministic model for the three technologies have been shown, the stochastic model is developed, for which the Monte Carlo model will be used to simulate the input variables that have the greatest impact on the LCOEE for each of the technologies.

\section{Estimation of the Levelized Cost of Electricity with Environmental Externalities using the Stochastic Method}

The stochastic method's objective is to incorporate historical information of the main input variables through probability density functions, which allows incorporating more information when generating the output variables. The preceding is of the utmost importance when evaluating longterm investment projects, as is the case at hand, where it is unlikely that the input variables will remain constant.

The Monte Carlo simulation is used for problems with complex operating conditions (involving a relatively high number of events), which, for several years, is being applied in the electric power generation industry (Feldman, 2010). It should be noted that the Monte Carlo simulation will only deliver data as accurate as of the model to which it is applied, so having a complete understanding of the problem is vital for the results obtained to be relevant ( $\mathrm{Li}, 2013)$.

It is increasingly common among analysts in the electricity sector to use stochastic methods for more robust decision-making in projects involving large investments. Such as those presented in this document (baseload power generation plants) (Feldman, 2010) (Hrafnkelsson, 2016) (Rode, 2001) (Roques F. , 2006) (Vithayasrichareon P. a., 2010) (Khindanova, 2013). 
This section uses historical information of the input variables $X_{-}(1 t,) X_{-}(2 t, \ldots,) X_{-} n t, t=1,2$, ..., $\mathrm{T}$, under its associated probability density function $\mathrm{f}_{-} \mathrm{j}$ ( $\mathrm{x}_{-} \mathrm{it}$ ), $\mathrm{j}=1,2, . ., \mathrm{n}$. Using the cumulative probability distribution function of each of the input variable's best fit, it is possible to simulate their behavior in different scenarios (Feldman, 2010) and estimate the expected value of different variables (Li, 2013).

The input variables considered in this document are; the overnight cost (Nuclear Energy Agency (NEA) e International Energy Agency (IEA), 2015), the monthly discount rate CIRR (Commercial Interest Reference Rate) in the period January 2009 to November 2017 published by the OECD (OECD Organisation for Economic Co-operation and Development, 2017), and the daily historical price of $\mathrm{CO}_{2}$ emissions from January 2012 to December 2017.

The specialized software @Risk version 7.5 of the Palisade company is used to estimate the distribution functions and perform the Monte Carlo simulation.

\subsection{Density Functions of the input parameters - Stochastic Method}

Little data is available on the unit investment costs of the three technologies. Only the maximum, minimum and average values are available (Nuclear Energy Agency (NEA) e International Energy Agency (IEA), 2015). Therefore, it is assumed that the random variables of the levelized investment cost are distributed according to triangular probability densities ${ }^{4}$ as shown in Table 5.

Table 5. Levelized investment cost of Coal Thermoelectric, Combined Cycle and Nuclear Plant

\begin{tabular}{|l|c|c|c|}
\hline \multicolumn{4}{|c|}{ Overnight Cost - USD/kWe } \\
\hline & CT & CC & Nuclear \\
\hline Maximum value & 3,067 & 1,289 & 6,217 \\
\hline Minimum value & 2,080 & 1,014 & 4,480 \\
\hline Media & 2,470 & 1,108 & 5,240 \\
\hline Standard deviation & 214 & 64 & 363 \\
\hline
\end{tabular}

Based on data obtained from (Nuclear Energy Agency (NEA) e International Energy Agency (IEA), 2015).

In the case of the discount rate, the Commercial Interest Reference Rates (CIRR) (OECD Organisation for Economic Co-operation and Development, 2017) has been taken as a reference, which is the interest rate applied in the countries of the Organization for Economic Cooperation and Development (OECD), of which Mexico is a member, to finance long-term projects. A monthly series is considered for the period from January 2009 to November 2017. An adjustment factor that includes the country risk of Mexico has also been included, which on September 1, 2017, was at the 181 basis point, according to the Secretariat of Treasury and Public Credit. (Secretaría de Hacienda y Crédito Público, 2017). The CIRR series is shown in Image 2.

\footnotetext{
${ }^{4}$ See chapter 44 of Forbes et al. (Forbes C., 2011)
} 


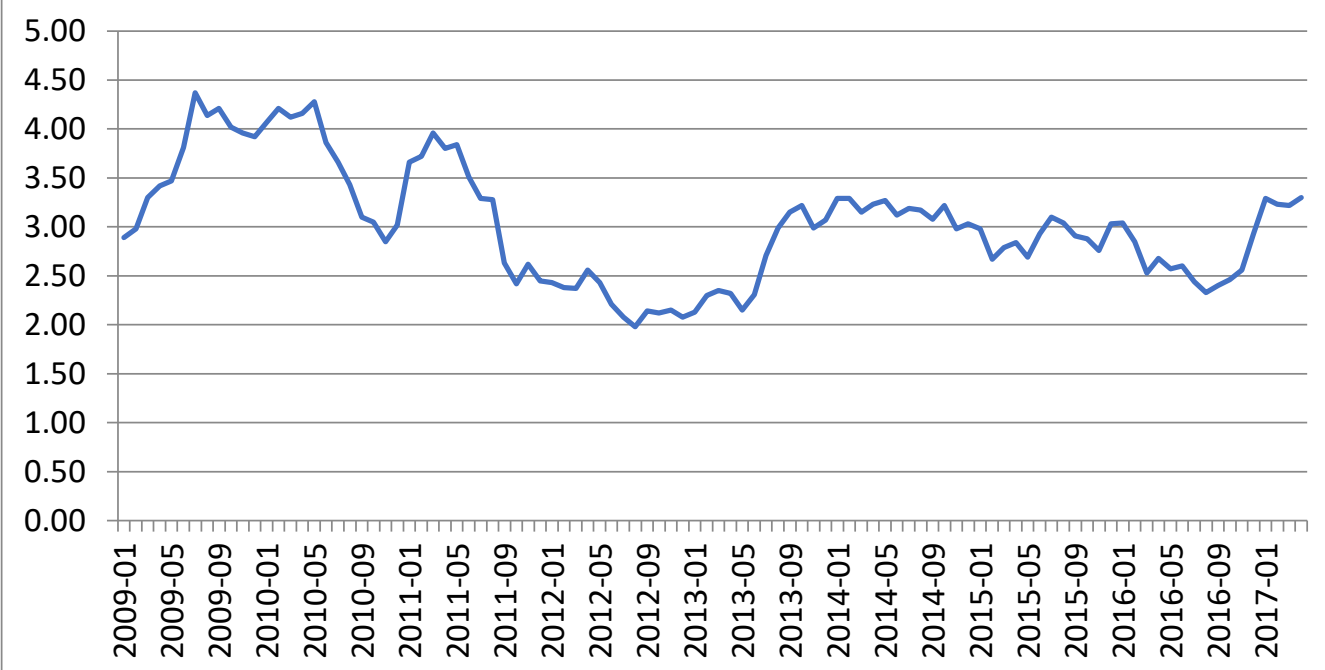

Image 2. Historical behavior of the CIRR.

Source: Based on data obtained from OECD OrganizationforEconomic Co-operation and Development, 2017.

Under this set of information, the probability density function that best fits is a Weilbull, with a mean of 3.0309 and a standard deviation of 0.5970 . The parameters were adjusted according to the following expression:

$$
\begin{gathered}
\text { máx } l=\sum_{j=1}^{n} \ln \left[f_{i}\left(x_{j t}\right)\right] \\
f_{i}\left(x_{j t}\right)=\left\{\begin{array}{cl}
\frac{\beta}{\alpha}\left(\frac{x_{j t}}{\alpha}\right)^{\beta-1} \exp \left[-\left(x_{j t} / \alpha\right)^{\beta}\right] & \text { si } x_{j t} \geq 0 \\
0 & \text { si } x_{j t}<0
\end{array}\right.
\end{gathered}
$$

Image 3 shows that there is a $91.9 \%$ probability that the CIRR is in the range of $2.13 \%$ and $4.14 \%$.

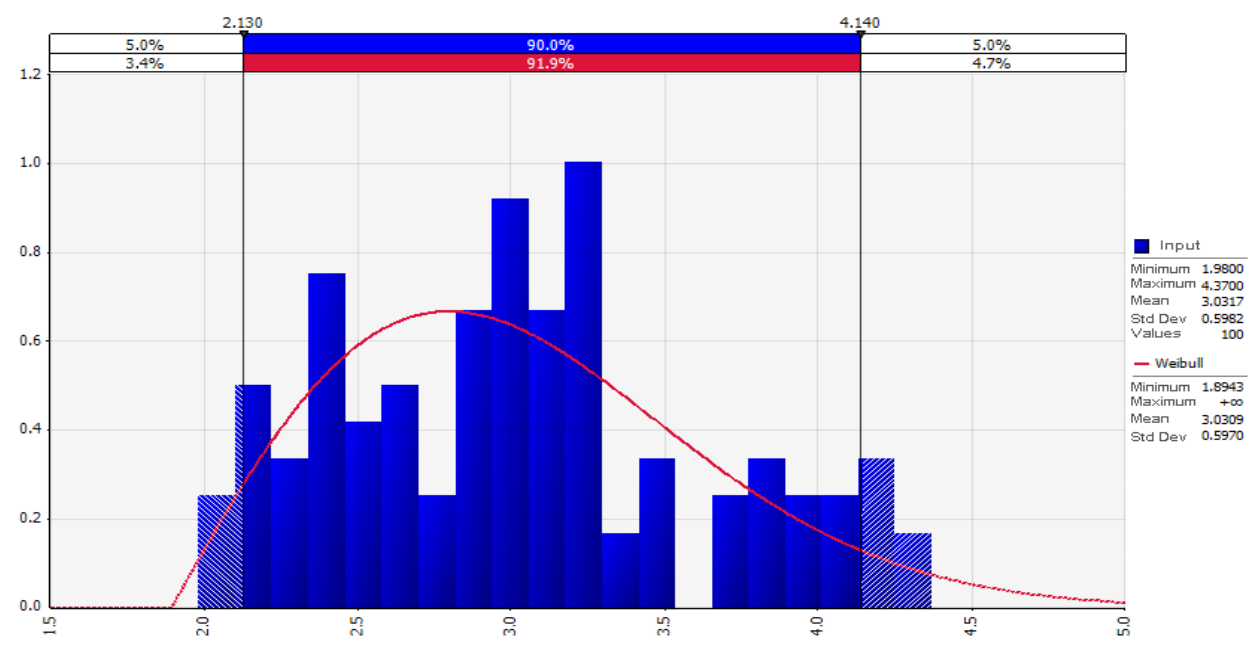

Image 3. Distribution of Probability of the CIRR.

Source: Own elaboration, generated with software CRisk. 
Considering the average distribution function of the CIRR and the country risk, an interest rate is estimated to obtain level of $4.84 \%$.

In order to assess the $\mathrm{CO}_{2}$ emissions of fossil fuel technologies, the historical series of closing prices per tonne of $\mathrm{CO}_{2}$, published in the webside Market insider, is used. The historical series is daily for the period from January 30, 2012, to December 15, 2017, and is shown in Image 4.

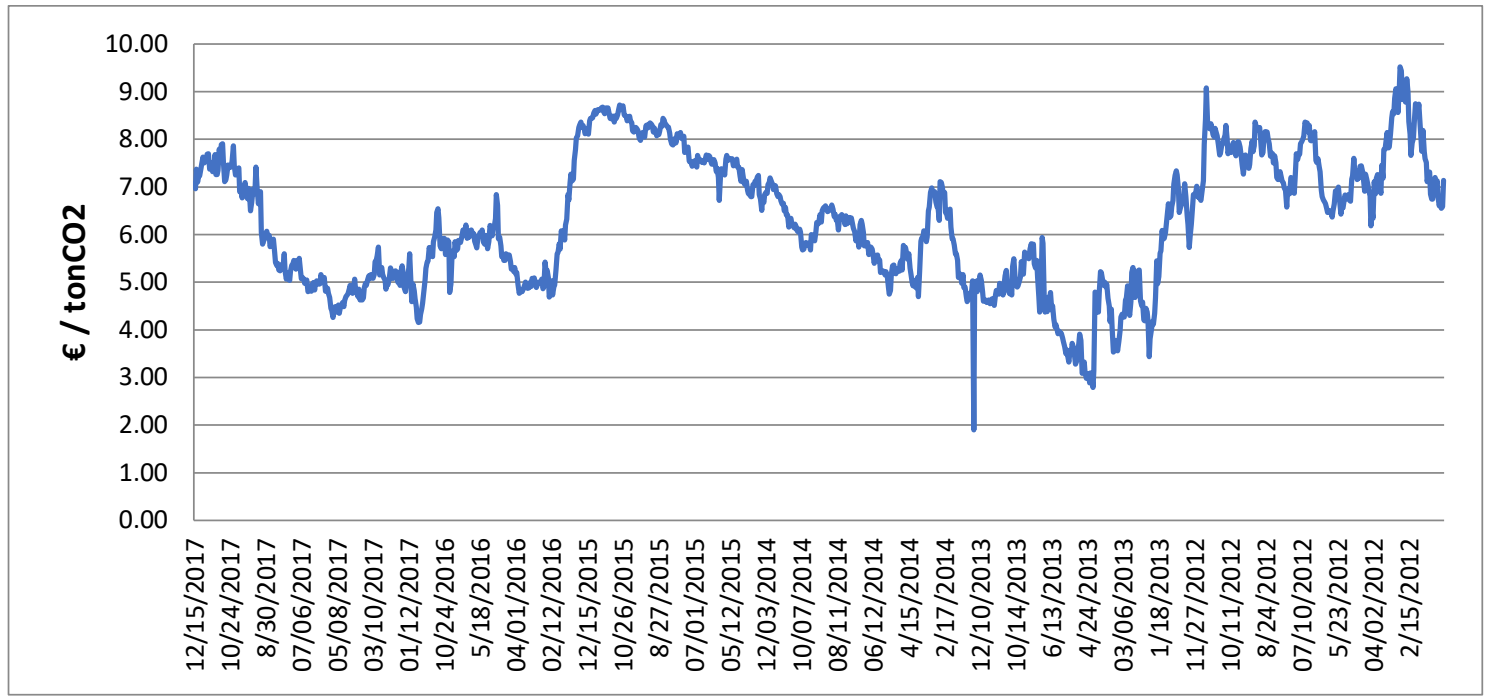

Image 4. Historical series of the Price per ton of $\mathrm{CO}_{2}$.

Source: Based on data from Market insider (Markets Business Insider, 2017).

From Image 4, the maximum, minimum and average value were selected, and a triangular distribution was adjusted, as shown in Table 6.

Table 6. Triangular distribution applied to historical prices per ton of $\mathrm{CO}_{2}$

\begin{tabular}{|l|c|}
\hline \multicolumn{2}{|l|}{ Price of $\mathrm{CO}_{2}$ emissions - Euros/Ton $\mathrm{CO}_{2}$} \\
\hline Maximum & 9.52 \\
\hline Minimum & 1.90 \\
\hline Media & 5.90 \\
\hline Standard deviation & 1.56 \\
\hline
\end{tabular}

Source: Based on data from (Markets Business Insider, 2017)

Considering an exchange rate for the period January 2012-November 2017 of 1.2690 USD per euro, an average price of $\mathrm{CO}_{2}$ emissions of $\$ 7.4892$ USD / ton $\mathrm{CO}_{2}$ is obtained. 


\subsection{Monte Carlo Simulation Results - Stochastic Method}

This section considers the distribution functions of the input parameters of the three analyzed technologies, applying the @RISK 7.5 software, and 100,000 iterations are performed to estimate the LCOEE means. In the case of the coal thermoelectric plant, an average LCOEE of \$ 80.40 USD / MWh was generated, a standard deviation of \$ 2.33 USD / MWh and a probability that the LCOEE is in the range of \$ 60 to \$ 80 USD / MWh of $44.2 \%$. While, for the combined cycle, the average is \$66.54 / MWh, a standard deviation of \$2.82 USD / MWh and a probability that the LCOEE is in the range of \$ 60 to $\$ 80$ USD / MWh of 99.1\%. While the nuclear power plant (ABWR) has an average of \$ 62.0 USD / MWh, a standard deviation of \$5.30 USD / MWh and a probability that the LCOE is in the range of $\$ 60$ to \$ 80 USD / MWh of $60.6 \%$. Image 5 shows the results of the three technologies, while Table 7 presents the main characteristics of the above mentioned probability densities.

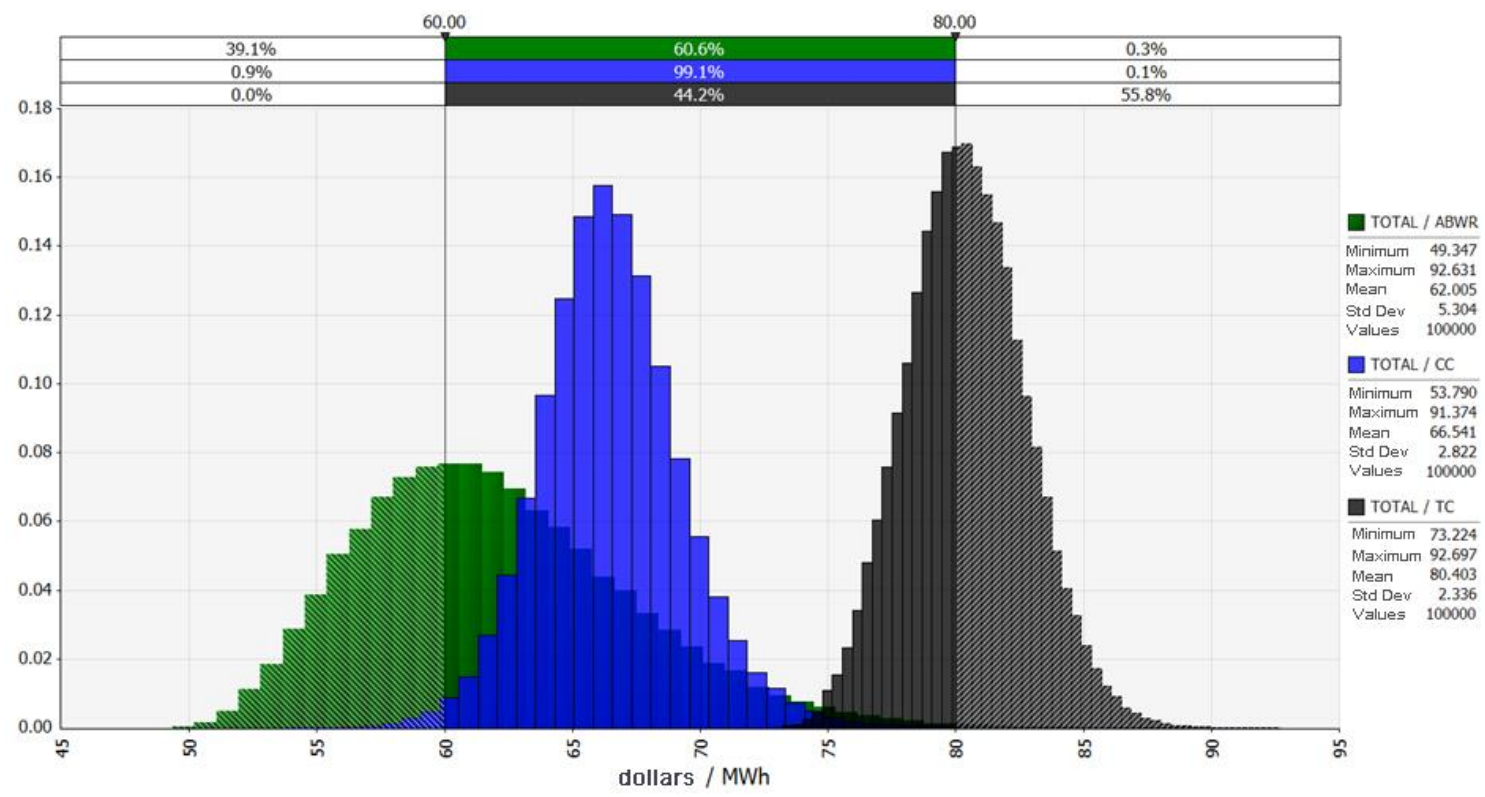

Image 5. Comparison of probability distribution functions of the LCOEE Coal Thermoelectric, Combined Cycle and Nuclear Plant, Stochastic Method.

Source: Own elaboration with data obtained from the simulation.

Table 7. Monte Carlo simulation

\begin{tabular}{|l|c|c|c|}
\hline \multicolumn{4}{|c|}{ LCOEE - USD/MWh } \\
\hline & CT & CC & Nuclear \\
\hline Maximum & 92.70 & 91.37 & 92.63 \\
\hline Minimum & 73.22 & 53.79 & 49.35 \\
\hline Media & 80.40 & 66.54 & 62.00 \\
\hline Standard deviation & 2.34 & 2.82 & 5.30 \\
\hline
\end{tabular}

Source: Own elaboration with data obtained from the simulation. 


\subsection{Tornado Analysis - Stochastic Method}

This section presents the tornado analysis for the three technologies under study, in which the impact that the main input parameters have on the LCOEE on each of the technologies is quantified.

In the case of thermoelectric coal plants, three input parameters are modified: the price of $\mathrm{CO}_{2}$ emissions (fdco2), the interest rate (fdtd1) and the overnight cost (cui-TC). It can be seen that the parameters that have the greatest impact on the LCOEE are the price of $\mathrm{CO}_{2}$ emissions and the interest rate. If there is a downward variation in the price of $\mathrm{CO}_{2}$ emissions (from the $5 \%$ to $95 \%$ percentile), the LCOEE goes from \$ 80.40 USD / MWh to \$ 77.51. While, if the interest rate has an upward movement, the LCOEE goes from \$ 80.40 USD / MWh to \$ 83.43. The parameter that has the least impact is the overnight cost. See Image 6.

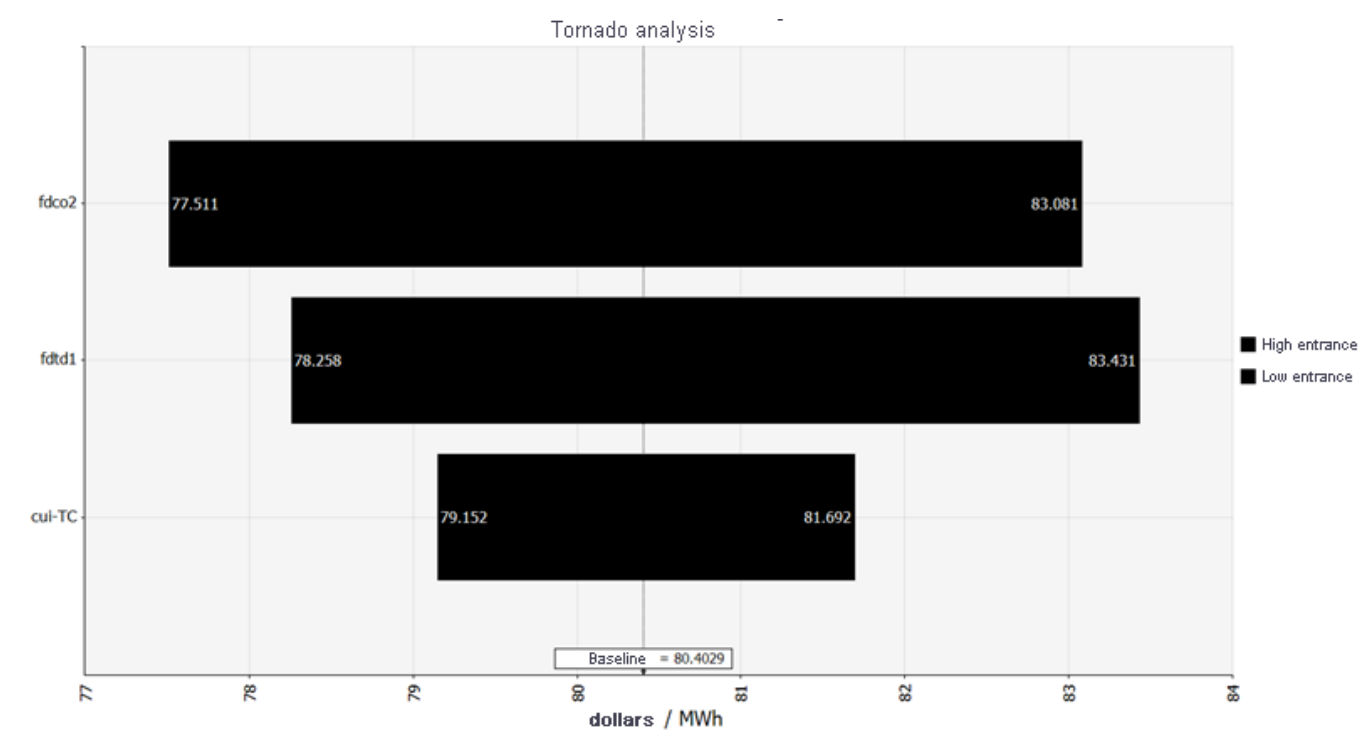

Image 6. Tornado Analysis - Coal Thermoelectric - Stochastic Method. Source: Own elaboration with data obtained from the simulation.

In the combined cycle, four input parameters are modified: the efficiency of the plants (fdeficCC), the price of $\mathrm{CO}_{2}$ emissions (fdco2), the overnight cost (cui-CC), and the interest rate (fdtd1). The parameter that has the greatest impact on the LCOEE is the efficiency of this type of plant since if there is an upward variation (from the $5 \%$ to $95 \%$ percentile), the LCOEE goes from $\$ 66.54$ USD / MWh to \$ 62.18 and if the variation is down, the LCOEE goes from \$ 66.54 USD / MWh to \$ 71.63. While it is not a capital-intensive technology such as the nuclear power plant, the parameter that has the least impact on the LCOEE is the interest rate, because if it is modified up or down, the impact is marginal. Image 7 shows the results of the combined cycle tornado analysis. 


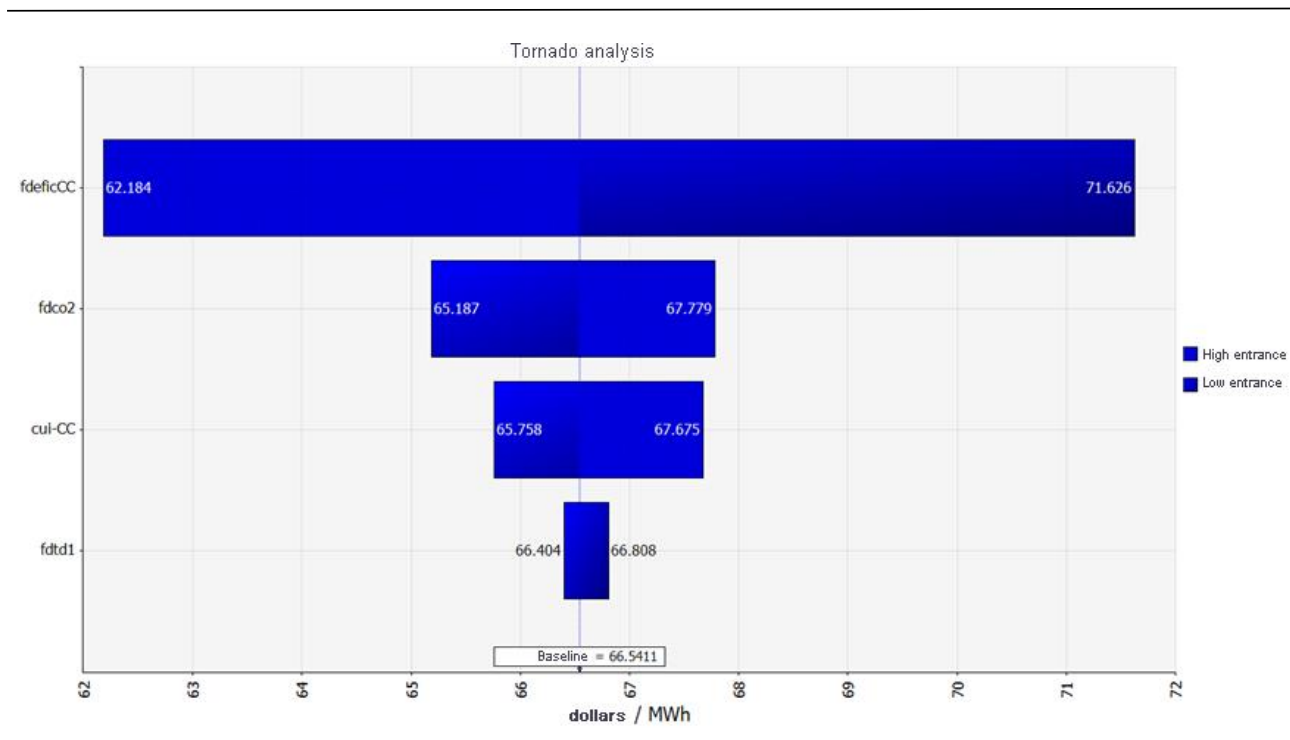

Image 7. Tornado Analysis - Combined Cycle - Stochastic Method.

Source: Own elaboration with data obtained from the simulation.

In the nuclear power plant, two input parameters are modified: the interest rate (fdtd1) and the overnight cost (cui-ABWR). Being a capital intensive technology, the parameter that has the greatest impact on the LCOE is the interest rate since if there is an upward variation (from the $5 \%$ to 95\% percentile), the LCOE goes from \$ 62.0 USD / MWh to \$ 70.88 and if the variation is down, it goes from \$62.0 USD / MWh to \$55.55. An upward change in the overnight cost impacts the LCOE from \$ 62.0 USD / MWh to \$67.25, and if the change is down, it goes from \$62.0 USD / MWh to \$ 57.69 .

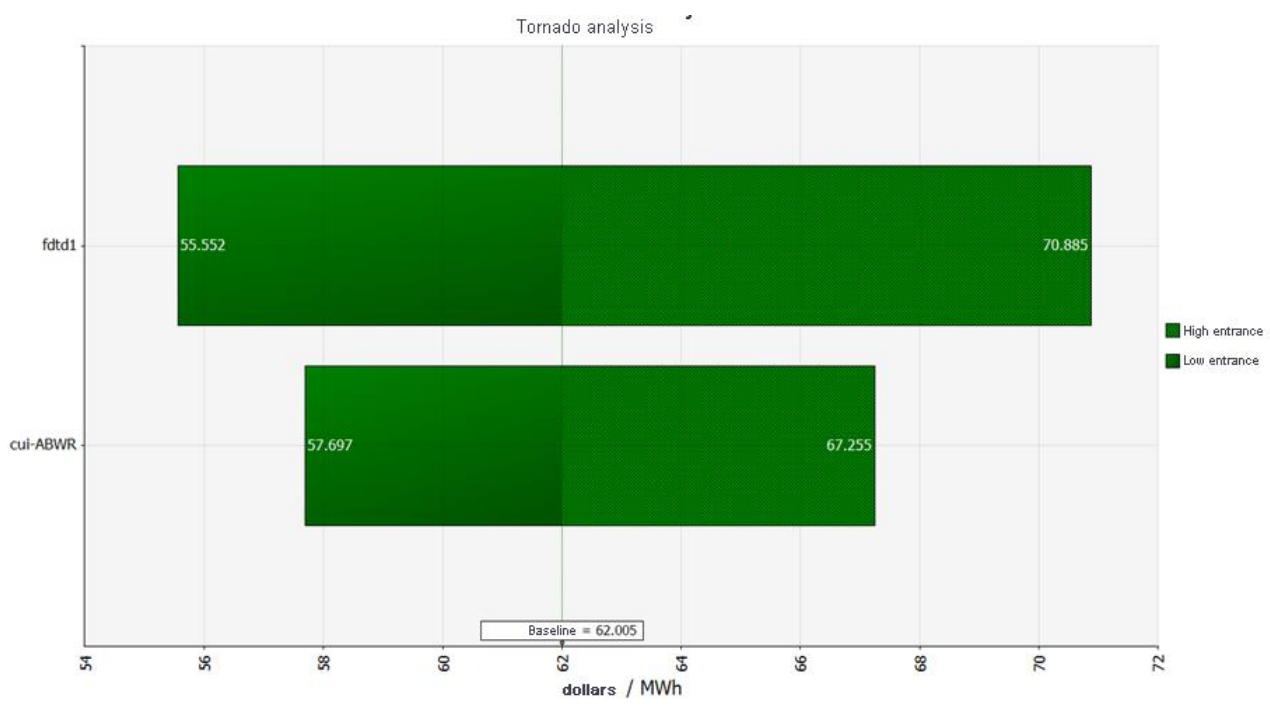

Image 8. Tornado Analysis - Nuclear Plant - Stochastic Method. Source: Own elaboration with data obtained from the simulation. 


\section{Comparison of Results of the Deterministic and Stochastic Model}

This section compares the results obtained in the deterministic method and the stochastic method. Image 9 shows the probability distribution functions obtained through Monte Carlo simulations for the technologies analyzed and their deterministic values.

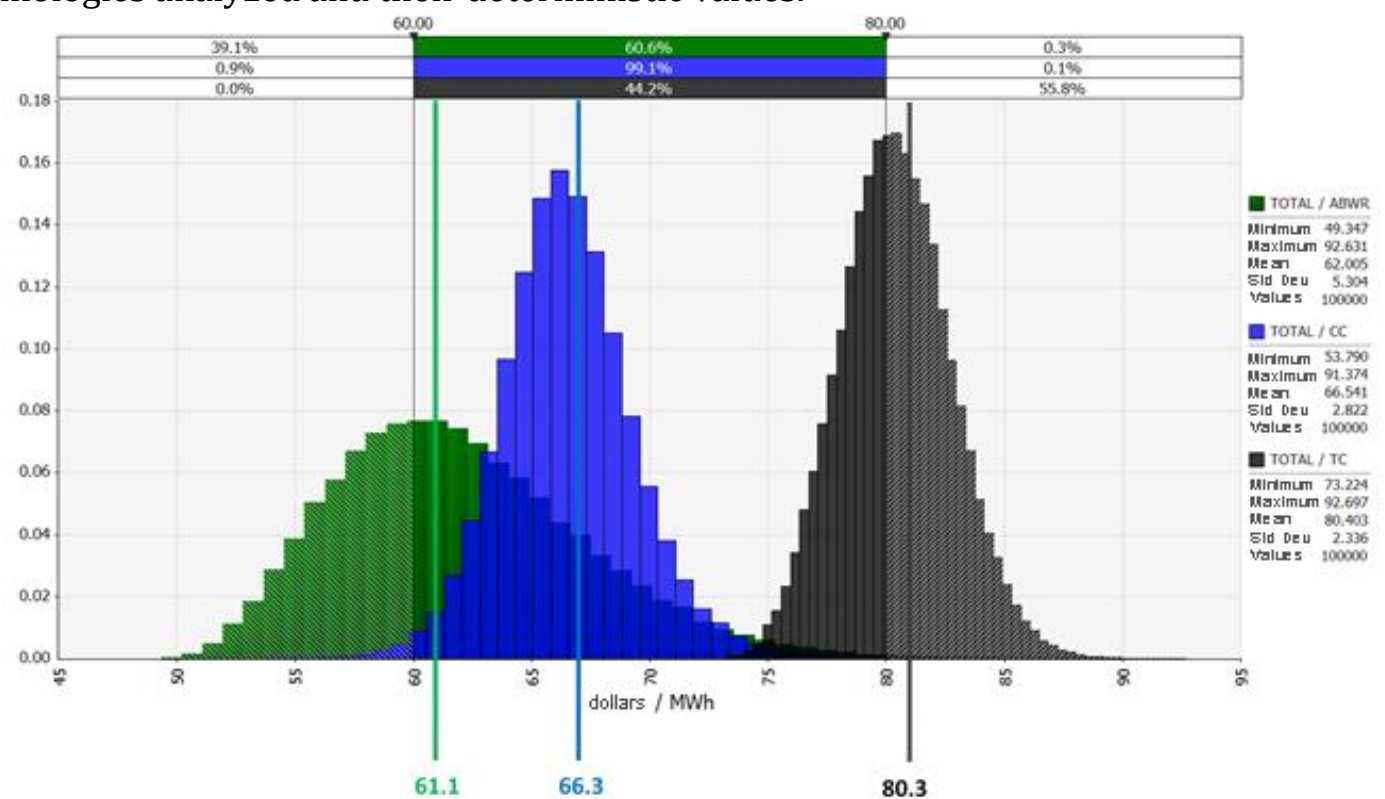

Image 9. Comparison of probability distribution functions of the LCOEE Coal Thermoelectric, Combined Cycle and Nuclear Plant - Deterministic and Stochastic Method. Source: Own elaboration with data obtained from the simulation.

When comparing the result obtained from the LCOEE with the deterministic method and the results of the stochastic model, it is observed that the stochastic model provides more information on the behavior of the output variable (LCOEE), which will be more useful in decision making.

\section{Discussion}

The deterministic model only provides an input parameter, which is not modified over the period considered, and the result is an output value. While the stochastic method incorporates probability distribution functions associated with the input variables, the use of specialized software (@Risk) facilitates calculations, reduces the execution time of the model, and provides a probability distribution image of the LCOEE values that are easily interpretable. Hence, allowing a more enriching decision making.

Incorporating the interest rate in the stochastic models is of great relevance for these types of capital intensive projects since any change in the interest rate has an essential effect on the plant's costs. 
In long-term projects, such as those presented in this work (coal thermoelectric, combined cycle, and nuclear power plants), stochastic models are recommended to identify the impact of changes in the input parameters on the output variable. They provide a clearer idea of the impact that each of the input variables can have on the LCOEE.

The LCOEE of the nuclear power plant is the one with the lowest median ( $\$ 62.0$ USD / MWh). However, it has the highest standard deviation and has a $60.0 \%$ probability that the LCOE ranks between 60 and 80 USD / MWh. While the combined cycle has a 99.1\% probability that the LCOEE rates in the same range, and the thermoelectric coal plant only have a $44.2 \%$ probability. With this information, it cannot be concluded that there is a technology that has the lowest LCOEE and, at the same time, the lowest risk.

The average price of $\mathrm{CO}_{2}$ emissions used in the stochastic model was $\$ 7.4892$ USD / ton $\mathrm{CO}_{2}$, a low price in relation to those proposed by the NEA / IEA in its 2015 publication, 30 USD / ton $\mathrm{CO}_{2}$. Even with the model's price, the impact on the LCOEE of fossil fuel technologies is significant. Obviously, the higher the price of $\mathrm{CO}_{2}$ that is used, the impact will be more significant.

In the tornado analysis of the thermoelectric coal plant, three variables were modified: the price of $\mathrm{CO}_{2}$ emissions, discount rate, and overnight cost, and it was found that the LCOEE is more sensitive to changes in the price of $\mathrm{CO}_{2}$ emissions since if this increases, the LCOEE goes from 80.4 to 83.08 USD / MWh, while if it decreases it falls to 77.5 USD / MWh.

In the combined cycle, four input variables were modified: plant efficiency, $\mathrm{CO}_{2}$ emissions price, discount rate, and overnight cost. The results show that the variable to which the LCOEE is most sensitive is the plant factor because if it increases, the LCOEE goes from 66.54 to 71.62 USD / MWh, while if it falls, it decreases to 62.18 USD / MWh. The second variable that most impacts the LCOEE is the price of $\mathrm{CO}_{2}$ because if it increases, the LCOEE goes from 66.54 to 67.78 USD / MWh, while if it decreases, the LCOEE goes to 65.19 USD / MWh.

Finally, for the tornado analysis of the nuclear power plant, two variables were considered: the discount rate and the overnight cost, with the discount rate being the one that has the greatest impact on the LCOE, since if the discount rate increases, the LCOE goes from 62.0 to 70.89 USD / MWh, while if it falls, the LCOE drops to 55.55 USD / MWh.

\section{Conclusions}

This research presented a comparison of the cost per MWh generated in baseload plants of electricity, coal thermoelectric, combined cycle, and nuclear power plants, also incorporated environmental externalities to coal and combined cycle plants' costs, to compare these technologies in equal circumstances with nuclear power plants that do not emit $\mathrm{CO} 2$ in their electricity generation process. The tornado analysis was used to identify each of the input variables' impact on the Levelized Cost Of Energy and Levelized Cost Of Energy with Externalities.

A deterministic method was applied to estimate the Levelized Investment Cost for the three technologies. In this method, the input parameters cannot be modified throughout the exchanges' operational life, and a single output result was obtained.

Externalities were added; $\mathrm{CO}_{2}$ in the thermoelectric coal plant and the combined cycle, and the levelized fuel cost were obtained. Then the levelized cost of electricity with environmental externalities was calculated. 
On the other hand, the levelized cost of electricity with environmental externalities was calculated using the stochastic model. The Monte Carlo model was used to simulate the input variables that significantly impact the LCOEE for each of the technologies.

When comparing the result obtained from the LCOEE with the deterministic method and the stochastic model results, it was observed that the stochastic model provided more information on the behavior of the output variable (LCOEE), which turns it into the most useful in decision making.

The results show that, in thermoelectric coal plants, the variables; price of $\mathrm{CO}_{2}$ emissions, discount rate, and overnight cost. The LCOEE is more sensitive to changes in the price of $\mathrm{CO}_{2}$ emissions.

In the combined cycle, the variables: plant efficiency, $\mathrm{CO}_{2}$ emissions price, discount rate, and overnight cost. The LCOEE is most sensitive to the plant factor.

In the nuclear power plant, variables: the discount rate and the overnight cost, the discount rate has the greatest impact on the LCOE.

This research's limitation is that the costs related to transmission, distribution, and backup fee are not included.

Hence, we can conclude that the LCOE is an indicator close to power generation plants' real investment costs in regulated markets, with regulated rates. That requires adjustments to incorporate the variations faced by electricity generators in liberalized markets, where fees are variable.

Stochastic models provide useful information for decision-making by incorporating historical data and projections of the main variables that could affect the output variable (LCOEE).

\section{Future work}

Future works considered are: apply the LCOE methodology to intermittent electricity generation technologies such as solar photovoltaic and wind, and compare the LCOE of this technologies with the baseload plants (Coal Thermoelectric, Combined Cycle and Nuclear Plant), using stochastic models.

\section{Aknowledgments}

The authors appreciate the valuable feedback from the reviewers to improve this work. 


\section{References}

[1] Agency, I. E. (2001). International emission trading - From Concept to Reality. International Energy Agency Paris. doi: https://doi.org/10.1787/9789264194915-en

[2] Agency, I. E. (2005). Act Locally, Trade Globally: Emissions Trading for Climate Policy. OECD Publishing. doi: https://doi.org/10.1787/9789264109544-en

[3] Aldersey-Williams, J., \& Rubert, T. (2019). Levelised cost of energy-A theoretical justification and critical assessment. Energy Policy, 124, 169-179. doi: https://doi.org/10.1016/j.enpol.2018.10.004

[4] Brown del Rivero, A., \& Brown del Rivero, A. (2011). Electricidad, características y opciones de reforma para México. Análisis Económico. https://www.redalyc.org/articulo.oa?id=41318401010

[5] Danish Energy Agency. $(2020,11$ 13). Finding your cheapest way to a low carbon future. Retrieved from The Danish Levelized Cost of Energy Calculator: https://ens.dk/sites/ens.dk/files/contents/material/file/introduction_lcoe_calculator.pdf

[6] De Roo, G., \& Parsons, J. E. (2011). A methodology for calculating the levelized cost of electricity in nuclear power systems with fuel recycling. Energy economics, 33, 826-839. doi:https://doi.org/10.1016/j.eneco.2011.01.008

[7] Eschenbach, T. (4 de 2006). Technical Note: Constructing Tornado Diagrams with Spreadsheets. The Engineering Economist, 51, 195-204. doi:10.1080/00137910600695676

[8] European Bank For Reconstruction And Development. (2014, 09 25). Methodology for the assessment of coal fired generation projects. Retrieved from https://www.ebrd.com/documents/climatefinance/methodology-for-the-assessment-of-coal-fired-generation-projects.pdf

[9] Faulín, J. J. (2005). Simulación de Monte Carlo con excel. Técnica Administraitva, 1 - 14. Retrieved 03 17, 2020, from https://isileiva.wordpress.com/?s=monte+carlo

[10] Federal Electricity Commission (CFE). (2014). Costos y Parámetros de Referencia para la Formulación de Proyectos de Inversión del Sector Eléctrico (COPAR). Subdirección de Programación, Comisión Federal de Electricidad.

[11] Feldman, R. a.-F. (2010). Applied Probability and Stochastic Processes. Springer. Retrieved from https://www.springer.com/gp/book/9783642051555

[12] Forbes C., E. M. (2011). Statistical Distributions. New York: Wiley. Retrieved from http://personalpages.to.infn.it/ zaninett/pdf/statistical-distributions.pdf

[13] Gómez-Ríos, M. d. (2016). Aplicación de modelos estocásticos en centrales nucleares generadoras de energía eléctrica para detectar el impacto que tiene la volatilidad de los mercados financieros en los costos nivelados de generación. In C. IMEF, Tópicos actuales de Finanzas (pp. 220 - 260). Guadalajara Jal, México.

[14] Gómez-Ríos, M.-d.-C. (2008, Octubre). La Energía Nuclear: una alternativa de generación de energía eléctrica de carga base en México. Doctoral Thesis.

[15] Hrafnkelsson, B. a. (2016). A Method for Estimating Annual Energy Production Using Monte Carlo Wind Speed Simulation. Energies, 9(4), 286. doi:https://doi.org/10.3390/en9040286

[16] IAEA Nuclear Energy Series. (2016). Preparation of a Feasibility Study for New Nuclear Power Projects. Training Course/Workshop on Feasibility Studies for Nuclear Power Projects. Beijing, China. Retrieved from https://www.iaea.org/publications/10505/preparation-of-a-feasibility-study-for-new-nuclearpower-projects

[17] Jamasb, T., \& Pollitt, M. (2005). Electricity Market Reform in the European Union: Review of Progress toward Liberalization \& Integration. The Energy Journal, 26, 11-41. Retrieved from http://www.jstor.org/stable/23297005 
REMEF (The Mexican Journal of Economics and Finance)

Simulation of Levelized Costs of Electricity Considering Externalities

[18] Johns Hopkins School of Advanced International Studies. (2017). Annual Energy Outlook. U.S. Energy Information Administration, Washington, D.C. Retrieved from https://www.eia.gov/pressroom/presentations/sieminski_01052017.pdf

[19] Karkhov, A. (2002). Economic evaluation of bids for nuclear power plants. Atomnaya Tekhnika za Rubezhom, 23 - 26. Retrieved from https://www.worldcat.org/title/economic-evaluation-of-bids-fornuclear-power-plants/oclc/44746390

[20] Khindanova, I. (2013). A Monte Carlo Model of a Wind Power Generation Investment. The Journal of Applied Business and Economics, 15(1), 94. Retrieved from http://digitalcommons.www.nabusinesspress.com/JABE/KhindanovaI_Web15_1_.pdf

[21] Li, W. (2013). Reliability assessment of electric power systems using Monte Carlo methods. Springer Science \& Business Media. Retrieved from https://books.google.com.mx/books/about/Reliability_Assessment_of_Electric_Power.html?id=qakA CAAAQBAJ\&redir_esc $=y$

[22] Locatelli, G., \& Mancini, M. (2010). Small-medium sized nuclear coal and gas power plant: A probabilistic analysis of their financial performances and influence of CO2 cost. Energy Policy, 38, 6360-6374. doi:https://doi.org/10.1016/j.enpol.2010.06.027

[23] Lucheroni, C., \& Mari, C. (2017). CO2 volatility impact on energy portfolio choice: A fully stochastic LCOE theory analysis. Applied Energy, 190, 278-290. doi:https://doi.org/10.1016/j.apenergy.2016.12.125

[24] Mari, C. (2020). Stochastic NPV Based vs Stochastic LCOE Based Power Portfolio Selection Under Uncertainty. Energies, 13, 3677. doi:https://doi.org/10.3390/en13143677

[25] Markets Business Insider. (2017, December 20). Retrieved from Markets Insider: https://markets.businessinsider.com/

[26] Matheu, M. (2014). Energy Driving Industrial Competitiveness. International Symposium: The Future of Industries. Retrieved from https://www.eu-japan.eu/sites/eu-japan.eu/files/seminars/Matheu.pdf

[27] NEA, O. E. (2003). Nuclear electricity generation: What are the external costs. Tech. rep., OECD. Retrieved from https://www.oecd-nea.org/jcms/pl_13756

[28] Nuclear Energy Agency (NEA) e International Energy Agency (IEA). (2015). Projected Costs of Generating Electricity. Retrieved from https://www.iea.org/reports/projected-costs-of-generatingelectricity-2015

[29] OECD Organisation for Economic Co-operation and Development. (2017). The arrangement for officially supported export credits. Retrieved from https://www.oecd.org/trade/topics/exportcredits/documents/cirrs.pdf

[30] Rabl, A., \& Spadaro, J. V. (2000). Public health impact of air pollution and implications for the energy system. Annual review of Energy and the Environment, 25, 601-627. doi:https://doi.org/10.1146/annurev.energy.25.1.601

[31] Riesz, J., Sotiriadis, C., Vithayasrichareon, P., \& Gilmore, J. (2017). Quantifying key uncertainties in the costs of nuclear power. International Journal of Energy Research, 41, 389-409.

[32] Rode, D. C. (2001). Monte Carlo methods for appraisal and valuation: a case study of a nuclear power plant. The Journal of Structured Finance, 7(3), 38 - 48. Retrieved from https://doi.org/10.3905/jsf.2001.320257

[33] Roques, F. (2006). Power generation investments in liberalised markets: methodologies to capture risk, flexibility, and portfolio diversity. Économies et Sociétés, 40(10/11), 1563. Retrieved from https://www.researchgate.net/publication/251818838_Analytic_Approaches_to_Quantify_and_Valu e_Fuel_Mix_Diversity1 
[34] Roques, F. A. (2006-07). Using Probabilistic Analysis to Value Power Generation Investments Under Uncertainty. Cambridge Working Papers in Economics (CWPE). doi:https://doi.org/10.17863/CAM.4961

[35] Secretaría de Hacienda y Crédito Público. (2017). Informe Semanal del Vocero. Retrieved from https://www.gob.mx/cms/uploads/attachment/file/181942/vocero_02_2017.pdf

[36] Shen, W., Chen, X., Qiu, J., Hayward, J. A., Sayeef, S., Osman, P., ... Dong, Z. Y. (2020). A comprehensive review of variable renewable energy levelized cost of electricity. Renewable and Sustainable Energy Reviews, 133, 110301. doi:https://doi.org/10.1016/j.rser.2020.110301

[37] Thomas F. Stacy, G. S. (2019, June). The Levelized Cost of Electricity from Existing Generation Resources. Retrieved from Institute for energy research: https://www.instituteforenergyresearch.org/wpcontent/uploads/2019/06/IER_LCOE2019Final-.pdf

[38] Thomas F. Stacy, G. S. (2019). The Levelized Cost of Electricity from Existing Generation Resources. Tech. rep., Institute for energy research. Retrieved from https://www.instituteforenergyresearch.org/wpcontent/uploads/2019/06/IER\_LCOE2019Final-.pdf

[39] Vithayasrichareon, P. a. (2010). Electricity generation portfolio evaluation for highly uncertain and carbon constrained future electricity industries. IEEE PES General Meeting. Retrieved from https://doi.org/10.1109/pes.2010.5589354

[40] Vithayasrichareon, P. M. (2010). Electricity generation portfolio analysis for coal, gas and nuclear plant under future uncertainties. The 4th IASTED Asian conference on power and energy systems, AsiaPES. Retrieved from https://doi.org/10.2316/p.2010.701-027

[41] Wada, K. a. (2014). Quantitative risk assessment of rising electricity prices in Japan. Energy \& the Economy, 37th IAEE International Conference. Retrieved from https://www.researchgate.net/publication/264938381_Quantitative_risk_assessment_of_rising_elec tricity_prices_in_Japan 